Article

\title{
Formulation Optimization of Extemporaneous Oral Liquids Containing Naloxone and Propranolol for Pediatric Use
}

\author{
Maria Attebäck ${ }^{1,2}$, Bengt Hedin ${ }^{2}$ and Sofia Mattsson 1,* \\ 1 Department of Integrative Medical Biology, Umeå University, SE-901 87 Umeå, Sweden; \\ maria.atteback@apl.se \\ 2 APL (Apoteket Produktion \& Laboratorier AB), SE-141 75 Stockholm, Sweden; bengt.hedin@apl.se \\ * Correspondence: sofia.mattsson@umu.se; Tel.: +46-90-786-65-80
}

Citation: Attebäck, M.; Hedin, B.; Mattsson, S. Formulation Optimization of Extemporaneous Oral Liquids Containing Naloxone and Propranolol for Pediatric Use. Sci. Pharm. 2022, 90, 15. https:// doi.org/10.3390/scipharm90010015

Academic Editor: William

A. Donaldson

Received: 26 January 2022

Accepted: 18 February 2022

Published: 22 February 2022

Publisher's Note: MDPI stays neutral with regard to jurisdictional claims in published maps and institutional affiliations.

Copyright: (C) 2022 by the authors. Licensee MDPI, Basel, Switzerland. This article is an open access article distributed under the terms and conditions of the Creative Commons Attribution (CC BY) license (https:// creativecommons.org/licenses/by/ $4.0 /)$.

\begin{abstract}
There is a need to develop dosage forms suitable for children to improve drug treatment. Extemporaneous compounding of drugs for children is one way to meet these needs. However, excipients generally considered as safe in adults may not be appropriate in dosage forms intended for children. The aim was to optimize the composition of two pediatric liquid preparations by substituting paraben as a microbiological preservative and ethanol as a solubilizer, with excipients more suitable for pediatric use. The oral liquids were Naloxone $1 \mathrm{mg} / \mathrm{mL}$ and Propranolol $10 \mathrm{mg} / \mathrm{mL}$. Twelve different formulations were tested with propranolol and naloxone, respectively, during the screening process to select appropriate formulations. Sodium benzoate and glycerol were used as a preservative and solubilizer, respectively, and different $\mathrm{pH}$ of the formulations were evaluated. The formulations were characterized according to dispensed dose (dosing accuracy), viscosity and osmolality. The optimized formulations from the screening process were tested with two amounts of sodium benzoate and microbiological assays were performed. These formulations were shown to have satisfactory preservative properties and dosing accuracy. The results showed that the oral liquids could be prepared without the addition of solubilizer and with lower osmolality (naloxone), thus reducing the risk of gastrointestinal side effects.
\end{abstract}

Keywords: extemporaneous compounding; oral liquid; preservative; solubilizer; pediatric use

\section{Introduction}

Extemporaneous compounding of drugs for children is used in order to meet the need for drug formulations and doses suitable for children. Many drugs are administered orally and only available as solid oral dosage forms, mainly tablets. These may be unsuitable for children due to lack of appropriate doses and swallowing difficulties among young children. Furthermore, off-label use of medicine is a common practice in the pediatric population [1] In addition, it may be difficult to divide a commercially available solid dosage form in a correct and reproducible manner when administering the medicine to children [2-4]. Modifications of solid oral dosage forms, such as tablet splitting, tablet crushing, and capsule opening can potentially affect therapeutic outcomes for patients and adverse events have been reported because of medicine modifications $[5,6]$. Consequently, there is a need for suitable pediatric formulations to improve drug treatment of children [7-12]. Oral suspensions and solutions may be an alternative to solid oral dosage forms and if no commercial liquid formulation is available, these can be manufactured extemporaneously. Oral liquid formulations can be rather easily manufactured extemporaneously, can provide flexibility regarding dosing and administration, and are easy to swallow [13-15]. One way of preparing extemporaneous oral liquids is to use commercially available solid oral dosage forms such as tablets and capsules, for example crushing of tablets or opening of capsules and adding water or another vehicle. When preparing an extemporaneous compound for pediatric use, the starting compound is often intended for adults and this needs to be taken 
into consideration. One major concern regarding liquid formulations is their stability [16]. Microbiological preservatives are generally added to the formulation to prevent growth of microorganisms and improve stability and shelf life. Another issue that needs to be addressed is taste, thus ensuring a formulation that will be acceptable to the pediatric population [13-15]. Osmolality and viscosity are also important properties to take into consideration when formulating oral liquids. Viscosity may affect the acceptability and palatability of the formulation and dosing accuracy [17]. Osmolality should not exceed $700 \mathrm{mOsm} / \mathrm{kg}$ in oral liquids to minimize gastrointestinal side effects [18]. Choosing excipients suitable for children is another challenge when developing pediatric formulations since excipients generally considered safe in adults may not be appropriate in dosage forms intended for children $[19,20]$.

There are several reasons to use microbiological preservatives in liquid formulations, e.g., to protect the user against microbial infections and to prevent chemical or physical changes caused by microorganisms, which in turn can affect the stability and the appearance of the formulation. Preservation of a liquid formulation can be achieved by altering the physicochemical properties, e.g., $\mathrm{pH}$, of the formulation or by adding a chemical substance to prevent microbial growth [21]. According to literature, $\mathrm{pH}$ between 2 and 9 can be tolerated in oral solutions and $\mathrm{pH}$ of a pharmaceutical solution is a compromise between solubility and stability as well as excipient functionality and physiological acceptability [22].

The optimal microbiological preservative should be effective against a broad spectrum of microorganisms. Most microbiological preservatives are weak acids and bases and, consequently, the $\mathrm{pH}$ of the formulation will affect the microbial effect of the preservative [21]. Type and properties of the dosage form and safety issues also need to be taken into account when choosing a suitable preservative. Safety issues are of particular importance in the pediatric population. Properties such as adequate solubility, an acceptable taste and smell, compatibility with active pharmaceutical ingredients (API), excipients and packaging, environmentally safety, broad antimicrobial spectra, low toxicity, effective in low concentrations, and costs need to be considered when choosing an appropriate preservative [21]. However, a single preservative does not possess all these properties; in some cases, it is a matter of choosing the least unsuitable preservative.

Some excipients, such as propylene glycol, ethanol, sorbitol and parabens, are considered potentially harmful in children [19]. In a recent publication, Rouaz et al. critically reviewed the use of excipients in the pediatric population and emphasized the need for safe and appropriate excipients for children [20]. In addition, Zupanets et al. compiled information of excipients used in pediatric cough syrups and concluded that most of the investigated formulations contained excipients potentially harmful to the pediatric population [23]. The safety of excipients used especially in infants, where metabolic and elimination pathways are not yet fully developed and who are more susceptible to adverse effects, must be taken into consideration [24]. Therefore, the selection of appropriate excipients in pediatric formulations is challenging. Parabens such as methyl parahydroxybenzoate (methylparaben) and propyl parahydroxybenzoate (propylparaben) are used as microbiological preservatives in drug formulations and in extemporaneous compounding of oral liquids. Parabens are regarded as "generally recognized as safe" (GRAS) by the Food and Drug Administration (FDA) in the USA [25]. Concern has been raised regarding the use of parabens in drug formulations regarding their negative effects on the endocrine system [26]. For example, in 2015 European Medical Agency (EMA) published a reflection paper regarding the use of parabens as excipients in oral formulations [27]. At present, there are not enough clinical data to support a change of recommendations of their use, but a limitation on their use in children could be warranted. In the STEP (Safety and Toxicity of Excipients for Paediatrics) database, information regarding excipients and their use in pediatrics is compiled and this information can be used to facilitate the selection of appropriate excipients [28]. Some studies have shown that parabens may be unsuitable for children. One study conducted kinetic modelling based on blood samples from newborns and showed that a daily exposure of drugs containing methylparaben can cause prolonged 
exposure due to unmetabolized methylparaben [29]. Another study showed that there was a risk of hyperbilirubinemia in newborns, since methylparaben can bind to albumin and thus displace bilirubin [30]. This risk was also observed with propylparaben in children younger than six months [31].

Ethanol is used as a solvent in oral liquid preparations. In extemporaneous compounding of oral liquids, a stock solution of paraben in ethanol is often used due to the low aqueous solubility of paraben and to facilitate manufacturing. Treating, for example, chronic conditions in children with drug formulations containing ethanol may lead to acute and chronic intoxication, and ethanol can affect both absorption and metabolism of drugs when administered at the same time $[9,24]$. One study showed that children treated with dosage forms containing ethanol in some cases obtained amounts exceeding half of the safe weekly consumption in adult women [32]. Another study showed that infants and newborns can be exposed to amounts of ethanol exceeding $6 \mathrm{mg} / \mathrm{kg} /$ day during drug treatment [33]. Regular exposure (weekly) of ethanol in small amounts is contraindicated for children younger than six years [9].

Two different oral liquids were included in the present study: Naloxone $1 \mathrm{mg} / \mathrm{mL}$ and Propranolol $10 \mathrm{mg} / \mathrm{mL}$. These oral liquids are extemporaneously manufactured by Apotek Produktion \& Laboratorier AB (APL) in Sweden. The choice of these two preparations was based on use (i.e., pediatric use), composition (i.e., original composition containing paraben and ethanol), and production volume (i.e., high production volume). Naloxone is used in the treatment of opioid-induced constipation and propranolol is used in the treatment of arrhythmia and hypertension. The physicochemical properties of naloxone and propranolol are presented in Table 1.

Table 1. Physicochemical properties of the active pharmaceutical ingredients used in the liquid formulations [34-37].

\begin{tabular}{ccc}
\hline Property & Naloxone & Propranolol \\
\hline $\mathrm{pH}$ stability (drug) & $2.5-5.0$ & $2.8-4.0$ \\
$\mathrm{pH}$ stability (product) & $3.0-4.0$ & $\leq 3$ \\
$\mathrm{pKa}$ & $7.84-10.07$ & 9.42 \\
Water solubility (drug) $(\mathrm{mg} / \mathrm{mL})$ & 5.64 & 0.079 \\
Water solubility (hydrochloride salt) $(\mathrm{mg} / \mathrm{mL})$ & 50 & 10 \\
\hline
\end{tabular}

The aim of the study was to optimize the composition of two pediatric extemporaneous liquid preparations containing naloxone and propranolol by substituting paraben as a microbiological preservative and ethanol as a solubilizer, with excipients more suitable for pediatric use. The present study is a response to concerns raised by the European Medicines Agency (EMA), regarding safety for children when using parabens. Due to the lack of clinical data, EMA has not yet changed their recommendation for paraben use in liquid formulations, although some clinical studies indicate that parabens are not suitable for pediatric use.

\section{Materials and Methods}

\subsection{Materials}

Two different oral liquids were chosen to be included in the study: Naloxone $1 \mathrm{mg} / \mathrm{mL}$ and Propranolol $10 \mathrm{mg} / \mathrm{mL}$. These preparations are provided by APL in Sweden. An overview of the materials and their function in the oral liquids is given in Table 2. The original compositions of the two oral liquids are presented in Table 3. 
Table 2. An overview of the materials and their functions. API = Active pharmaceutical ingredient.

\begin{tabular}{|c|c|c|c|}
\hline Material & Function & Manufacturer & Country \\
\hline Naloxone hydrochloride dihydrate & API & Sanofi Chimie & France \\
\hline Propranolol hydrochloride & API & Cosma S.p.A. & Italy \\
\hline $\begin{array}{c}\text { Stock solution of methyl } \\
\text { parahydroxybenzoate } \\
\text { Ethanol } 96 \% \\
\text { Methyl parahydroxybenzoate } \\
\text { Water, purified }\end{array}$ & Preservative & $\begin{array}{l}\text { Univar } \\
\text { Merck KGaA } \\
\text { APL }^{1}\end{array}$ & $\begin{array}{l}\text { Sweden } \\
\text { Germany } \\
\text { Sweden }\end{array}$ \\
\hline Sodium benzoate & Preservative & $\begin{array}{l}\text { Emerald Performance } \\
\text { Materials }\end{array}$ & Netherlands \\
\hline Sodium citrate & Buffering agent & Jungbunzlauer AG & Austria \\
\hline Citric acid monohydrate & Buffering agent & Jungbunzlauer AG & Austria \\
\hline $\begin{array}{c}\text { Sugar syrup } 63 \% \\
\text { Sucrose } \\
\text { Methyl parahydroxybenzoate } \\
\text { Water, purified }\end{array}$ & $\begin{array}{c}\text { Sweetening agent, } \\
\text { viscosity-increasing agent }\end{array}$ & $\begin{array}{l}\text { Nordic Sugar AB } \\
\text { Merck KGaA } \\
\text { APL }\end{array}$ & $\begin{array}{l}\text { Sweden } \\
\text { Germany } \\
\text { Sweden }\end{array}$ \\
\hline $\begin{array}{c}\text { Glycerol 85\% } \\
\text { Glycerol } \\
\text { Water, purified }\end{array}$ & $\begin{array}{l}\text { Solvent, sweetening agent, } \\
\text { viscosity-increasing agent }\end{array}$ & Oleon NV & France \\
\hline Hydrochloric acid $1 \mathrm{M}$ and $5 \mathrm{M}$ & $\mathrm{pH}$ adjustment & Merck KGaA & Germany \\
\hline Water, purified & Solvent & APL & Sweden \\
\hline
\end{tabular}

Table 3. Original composition of the two oral liquids included in the study.

\begin{tabular}{ccc}
\hline Preparation & Material & Amount \\
\hline Naloxone $1 \mathrm{mg} / \mathrm{mL}$ & $\begin{array}{c}\text { Naloxone hydrochloride dihydrate } \\
\text { Methyl parahydroxybenzoate } 1 \\
(+6 \text { mg Ethanol } 96 \%)\end{array}$ & $1 \mathrm{mg}$ \\
& Hydrochloric acid 1 M & $1 \mathrm{mg}$ \\
& Water, purified & q.s. pH 3-3.5 \\
& ad $1 \mathrm{~mL}$ \\
\hline Propranolol $10 \mathrm{mg} / \mathrm{mL}$ & Propranolol hydrochloride & $10 \mathrm{mg}$ \\
pH 3.9 & Citric acid monohydrate & $2.1 \mathrm{mg}$ \\
& Sugar syrup & $2.8 \mathrm{mg}$ \\
& Methyl parahydroxybenzoate 1 & $320 \mathrm{mg}$ \\
& (+4.08 mg Ethanol 96\%) & $0.68 \mathrm{mg}$
\end{tabular}

${ }^{1}$ Methyl parahydroxybenzoate is used as stock solution containing $10 \%$ methyl parahydroxybenzoate (composition per $100 \mathrm{~g}$ : methyl parahydroxybenzoate $10 \mathrm{~g}$, ethanol $(96 \%) 60 \mathrm{~g}$, purified water $30 \mathrm{~g}$ ). ad = to; q.s. (quantum satis) $=$ the amount which is enough

\subsection{Choice of Preservative and Solubilizer}

There are several microbiological preservatives that are suitable for liquid formulations. Figure 1 shows a flow chart used to select an appropriate preservative to substitute methyl parahydroxybenzoate in liquid formulations intended for children. The following properties of the microbiological preservative were considered important: high water solubility, antimicrobial spectra similar to parabens, and good antimicrobial effects at the $\mathrm{pH}$ of the liquid formulations. Considering these different aspects of a preservative, sodium benzoate was chosen as the microbiological preservative [28,38-40]. In the original compositions, ethanol was primarily used as a solubilizer for the preservative and a stock solution of the preservative was used. Excluding ethanol in the formulation could poten- 
tially affect the solubility of the API and therefore an alternative solublizer was evaluated. Ethanol (0.4-0.6\%) was substituted by glycerol (0-20\%) in the formulations since glycerol has previously been shown to be well tolerated by children [41-43].

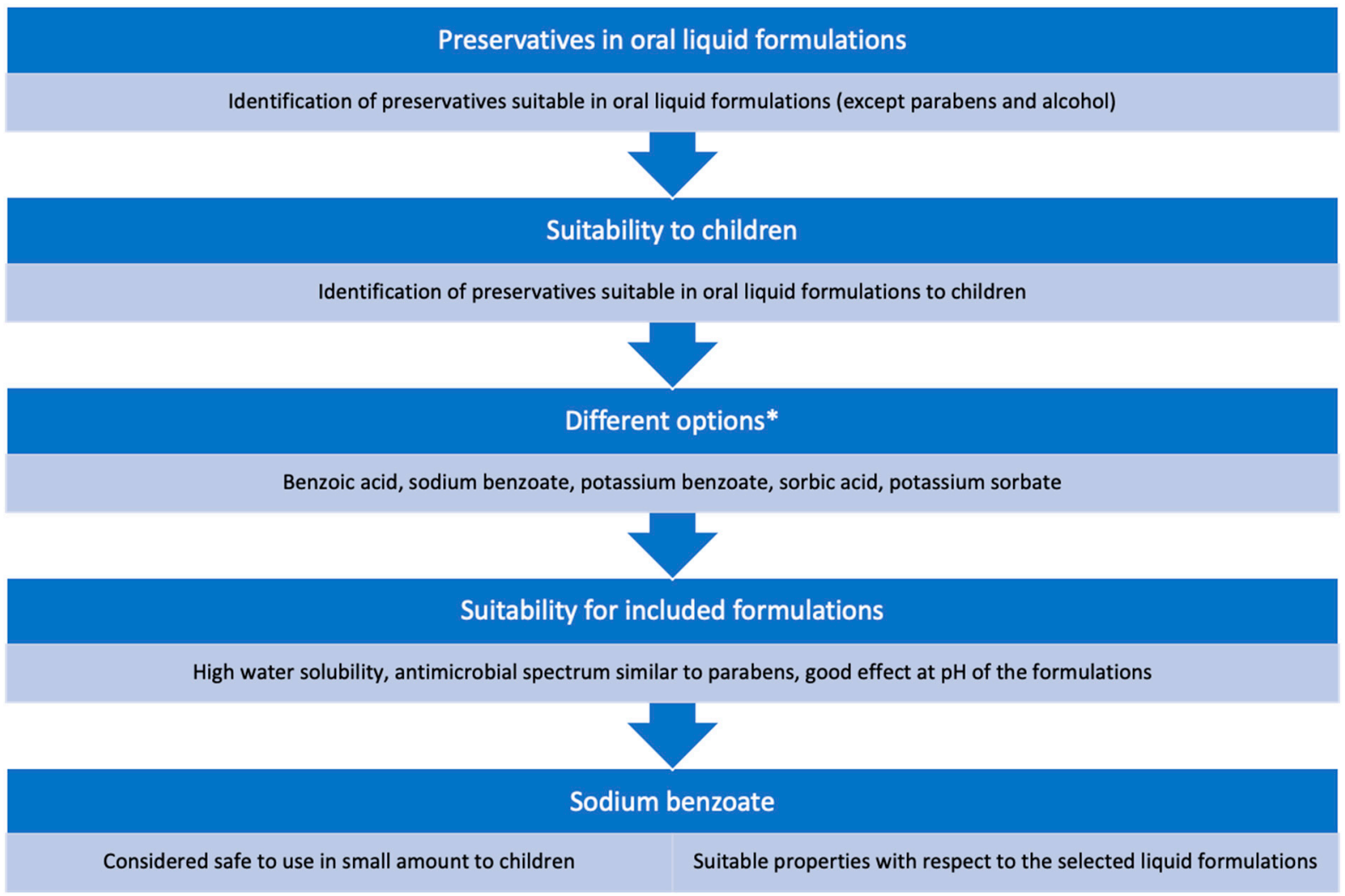

Figure 1. Flow chart describing the process to select an appropriate preservative in order to substitute methyl parahydroxybenzoate. * Benzoic acid: solubility in water at $20^{\circ} \mathrm{C} 1$ in 300 , optimal antimicrobial pH 2.5-4.5, effective against bacteria, fungi, mold and yeast. Sodium benzoate: solubility in water at $20^{\circ} \mathrm{C} 1$ in 1.8 , optimal antimicrobial $\mathrm{pH} 2-5$, effective against bacteria and fungi. Potassium benzoate: solubility in water at $20^{\circ} \mathrm{C} 1$ in 2.36 , optimal antimicrobial $\mathrm{pH} \leq 4.5$, effective against bacteria and fungi. Sorbic acid: insoluble in water, optimal antimicrobial $\mathrm{pH} 4.5$, effective primarily against fungi. Potassium sorbate: solubility in water at $20^{\circ} \mathrm{C} 1 \mathrm{in} 1.72$, optimal antimicrobial $\mathrm{pH}<6$, effective primarily against fungi $[8,22,28,38-40,44]$.

\subsection{Manufacture of the Liquid Formulations}

The liquid formulations were manufactured according to internal protocol at APL in Sweden. $50 \mathrm{~mL}$ was generally prepared. However, in the challenge tests, where the preservative effect was analyzed, a larger volume was required, and $500 \mathrm{~mL}$ was therefore manufactured in these tests. The excipients and API were first weighed. Glycerol (when included) and sugar syrup (when included) were first added to a volumetric flask and thereafter $80 \%$ of the stipulated amount of water. The remaining dry excipients were added one at a time while stirring. The $\mathrm{pH}$ was then adjusted, and the solution was diluted with water to the final volume. The original liquid formulations were manufactured and characterized regarding dispensed dose (dosing accuracy), osmolality and viscosity, and they were used as a baseline to compare with the corresponding characteristics of the modified formulations.

A small experiment was first performed to investigate the compatibility with the new preservative, sodium benzoate, and to obtain $\mathrm{pH}$ values of the formulations to be used in the subsequent design of experiments. The liquid formulations were prepared using sodium benzoate instead of methyl parahydroxybenzoate; the other ingredients were the same as in the original formulations. The concentration of sodium benzoate was set to $0.5 \%$, 
which is the highest recommended amount according to the Handbook of Pharmaceutical Excipients [44]. However, in the formulation containing propranolol, the concentration of sodium benzoate had to be reduced to $0.2 \%$ since a precipitate was observed, probably caused by the preservative. This precipitation was observed at $0.3 \%$ sodium benzoate.

\subsection{Experimental Plan}

To study the effect of substituting methyl parahydroxybenzoate and ethanol with sodium benzoate and glycerol more systematically, a design of experiment (DoE) approach was used. An experimental plan for the experiments was developed using MODDE Pro (Sartorius Stedim Biotech, Sweden). Variables included in the experiments were $\mathrm{pH}$ and amount of glycerol (\%). The $\mathrm{pH}$ interval was selected based on the results of the screening experiments and the stability of each API (Table 1). These variables were then combined according to the principle high/low, low/high, low/low and high/high. Tables 4 and 5 show the experimental plans for the liquid formulations.

Table 4. Design of experiments for Naloxone $1 \mathrm{mg} / \mathrm{mL}$. Name and order of experiments, $\mathrm{pH}$ to be set, and the amount of solubilizer (\%). N5, N10-12 are replicates. The amount of sodium benzoate was $0.5 \%$.

\begin{tabular}{ccccc}
\hline $\begin{array}{c}\text { Order of } \\
\text { Manufacturing }\end{array}$ & $\begin{array}{c}\text { Experiment } \\
\text { Number }\end{array}$ & $\begin{array}{c}\text { Experiment } \\
\text { Name }\end{array}$ & pH & Glycerol (\%) \\
\hline 1 & 7 & N7 & 3 & 20 \\
2 & 4 & N4 & 3 & 10 \\
3 & 3 & N3 & 4.5 & 0 \\
4 & 6 & N6 & 4.5 & 10 \\
5 & 2 & N2 & 3.75 & 0 \\
6 & 1 & N1 & 3 & 0 \\
7 & 9 & N9 & 4.5 & 20 \\
8 & 12 & N12 & 3.75 & 10 \\
9 & 11 & N11 & 3.75 & 10 \\
10 & 8 & N8 & 3.75 & 20 \\
11 & 5 & N5 & 3.75 & 10 \\
12 & 10 & & 3.75 & 10 \\
\hline
\end{tabular}

Table 5. Design of experiments for Propranolol $10 \mathrm{mg} / \mathrm{mL}$. Name and order of experiments, $\mathrm{pH}$ to be set, and the amount of solubilizer (\%). N5, N10-12 are replicates. Amount of sodium benzoate was $0.2 \%$.

\begin{tabular}{ccccc}
\hline $\begin{array}{c}\text { Order of } \\
\text { Manufacturing }\end{array}$ & $\begin{array}{c}\text { Experiment } \\
\text { Number }\end{array}$ & $\begin{array}{c}\text { Experiment } \\
\text { Name }\end{array}$ & pH & Glycerol (\%) \\
\hline 9 & 9 & N9 & 5 & 20 \\
3 & 3 & N3 & 5 & 0 \\
10 & 10 & N10 & 4 & 10 \\
5 & 5 & N5 & 4 & 10 \\
12 & 12 & N12 & 4 & 10 \\
8 & 8 & N8 & 4 & 20 \\
2 & 2 & N2 & 4 & 0 \\
7 & 7 & N7 & 3 & 20 \\
11 & 11 & N11 & 4 & 10 \\
1 & 1 & N1 & 3 & 0 \\
6 & 6 & N6 & 5 & 10 \\
4 & 4 & N4 & 3 & 10 \\
\hline
\end{tabular}

\subsection{Optimization and Evaluation Using MODDE Pro}

The following responses were used in the study; viscosity (mean value at $20 \mathrm{~s}^{-1}$ ), solubility $(1=$ soluble, $0=$ insoluble $)$ and dispensed dose. These responses were included in MODDE Pro when developing the design of experiments. A response contour plot was 
obtained for each liquid formulation. The variables $\mathrm{pH}$ and amount (\%) glycerol were also included. Based on the response contour plots, new compositions of optimal formulations were obtained. Liquid formulations based on these optimal formulations and with varied amounts of preservative were then manufactured and analyzed thereafter with respect to dispensed dose, viscosity, osmolality and preservative effect.

\subsection{Evaluation of Oral Liquids}

2.6.1. Solubility

Solubility of the API in the oral liquids was determined visually by ocular inspection of the vials after manufacturing.

\subsection{2. $\mathrm{pH}$}

The $\mathrm{pH}$ of the oral liquids was determined using a $\mathrm{pH}$ meter (Mettler Toledo Seven Multi, Mettler Toledo, Columbus, OH, USA). Hydrochloric acid (1 M or $5 \mathrm{M}$ ) or sodium hydroxide $(0.1 \mathrm{M}$ or $1 \mathrm{M})$ were added to adjust $\mathrm{pH}$ to the specified value. Measurements were conducted according to European Pharmacopoeia (Ph. Eur.) 2.2.3-Potentiometric determination of $\mathrm{pH}[45]$.

\subsubsection{Viscosity}

The viscosity of the oral liquids was determined using a rheometer (Discovery HR-1, TA Instruments, UK). Measurements were performed using a cone-plate, geometry $6 \mathrm{~cm}$ with a cone angle of $1^{\circ}$. A temperature of $20^{\circ} \mathrm{C}$, linear mode, and shear rate from 3 to $110 \mathrm{~s}^{-1}$ were used. Measurements were conducted according to Ph. Eur. 2.2.10-Viscosityrotating viscometer method) [45]. Measurements were performed in duplicate. The results are presented as mean values \pm coefficient of variation.

\subsubsection{Osmolality}

The osmolality of the oral liquids was measured using an osmometer (Mikro-Osmometer Automatic, Löser Messtechnik, Berlin, Germany). The osmometer was calibrated according to Ph.Eur. 2.2.35-Osmolality [45] using $100 \mu \mathrm{L}$ standard solution with known osmolality (300 mOsm $/ \mathrm{kg} \mathrm{H}_{2} \mathrm{O}$ ) (300 standard solution for osmometer (Löser Messtechnik, Germany)) instead of using Water $\mathrm{R}$ as specified in Ph.Eur. Measurements were conducted in duplicate. The results are presented as mean values \pm coefficient of variation.

\subsubsection{Dispensed Dose and Dosing Accuracy}

Dosing accuracy of the oral liquids was tested to evaluate the suitability of the liquid formulations together with the dosing device. A suitable dose was selected for each formulation based on use in children. For Naloxone $1 \mathrm{mg} / \mathrm{mL}$, the dose was set at $1 \mathrm{mg}$ $(1 \mathrm{~mL})$ based on doses previously used in pediatric patients [46]. Dropless adapters and dosing syringes $(5 \mathrm{~mL})$ were used to withdraw the doses. For Propranolol $10 \mathrm{mg} / \mathrm{mL}$, the dose was set at $5 \mathrm{mg}(0.5 \mathrm{~mL})$ based on a dose of $1-5 \mathrm{mg} / \mathrm{kg}$ bodyweight/day and assuming a bodyweight of $5 \mathrm{~kg}$ and dosing three times a day. Dropless adapters and dosing syringes $(1 \mathrm{~mL})$ were used to withdraw the doses. All doses were weighed on an analytical balance (Mettler Toledo XP603S, Mettler Toledo, USA). Density measurements of the solutions were performed using a density meter (DMA $4100 \mathrm{M}$, Anton Paar, Graz, Austria). The volume of the dose withdrawn by the syringe (dispensed dose) was used as a measure of dosing accuracy of the liquid formulations. The volume was calculated by dividing the weight of the dose with the density of the solution $(n=10)$. The results are presented as mean value $\pm 95 \%$ confidence interval. An acceptable dosing accuracy was set to $\pm 10 \%$ of target dose (volume) (according to internal guidelines at APL).

\subsubsection{Preservative Effect}

The preservative effect was evaluated using a challenge test for 28 days according to Ph.Eur. 5.1.3-Efficacy of antimicrobial preservation [45]. During the test, the oral liquids 
were challenged with different microorganisms and the liquids were stored at a prescribed temperature $\left(20-25^{\circ} \mathrm{C}\right)$. At specified time intervals, samples were withdrawn from the liquids and the number of microorganisms in the samples was counted. Two formulations containing naloxone and propranolol, respectively, were chosen. The formulations were chosen based on the evaluation in MODDE Pro. Two different amounts of preservative were tested $(0.05 \%$ and $0.1 \% w / v$ sodium benzoate).

\section{Results and Discussion}

Twelve different formulations (N1-N12) were tested with propranolol and naloxone, respectively, during the screening process to be able to select appropriate formulations (Tables 4 and 5). The formulations were characterized according to dispensed dose (dosing accuracy), viscosity and osmolality. The results were compared with the formulations with the original compositions (baseline).

\subsection{Dispensed Dose and Dosing Accuracy}

Figure 2 shows dispensed doses of the different formulations containing naloxone and propranolol, respectively, in comparison with the baseline formulations. The results showed that all formulations had an acceptable dosing accuracy and that there were small differences between the formulations. For naloxone formulations (N1-N12), the dosing accuracy, i.e., error in dispensed dose, varied between $0.2 \%$ and $4.4 \%$ and for propranolol formulations (N1-N12); the error in dispensed dose varied between $0 \%$ and $2.4 \%$.

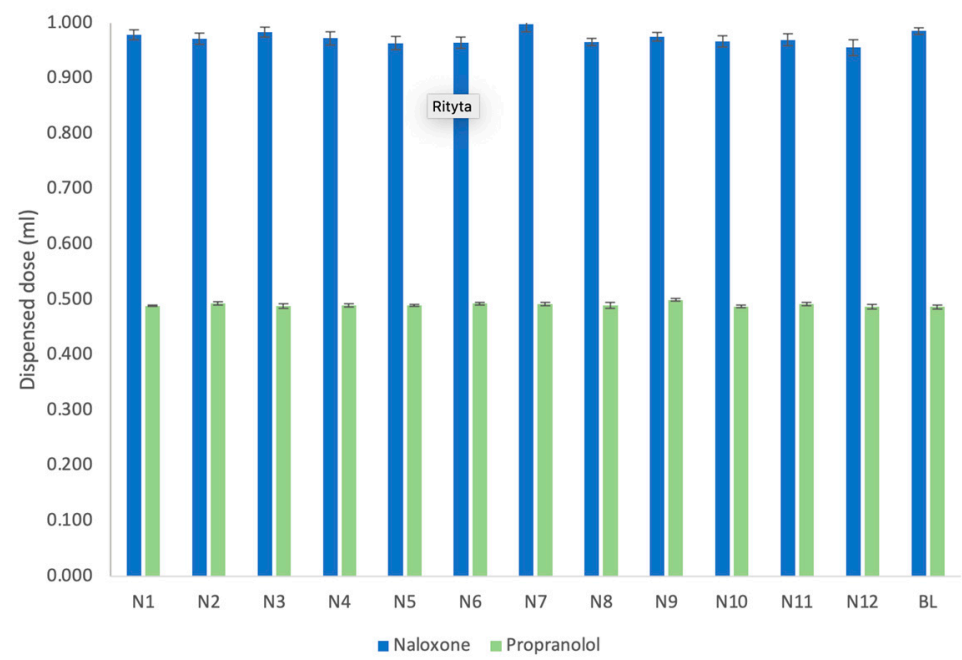

Figure 2. Dispensed dose (dosing accuracy) of formulations containing naloxone (blue) and propranolol (green). BL = baseline (original composition). Compositions of formulations N1-N12 according to Tables 4 and 5. Mean value with $95 \%$ confidence interval $(n=10)$. The target dose was $1 \mathrm{~mL}$ (corresponding to $1 \mathrm{mg}$ naloxone) and $0.5 \mathrm{~mL}$ (corresponding to $5 \mathrm{mg}$ propranolol). $\pm 10 \%$ of the target dose was considered an acceptable dosing accuracy.

The type of dosing device can affect dosing accuracy and studies have shown that using a syringe is generally better than a cup, dropper or spoon to accurately dispense a dose [47-50] but the suitability of a dosing device was also shown to be dependent on the viscosity of the liquid [47]. Furthermore, dosing accuracy is also related to consumer use and education of the consumer on the correct way to use a dosing device [47-50]. A high dosing accuracy of the formulation together with a, for the formulation, suitable dosing device is crucial in order ensure that a correct dose is administered [51,52]. The differences in dosing accuracy between the oral liquids containing naloxone and propranolol may be due to differences in syringes used ( $5 \mathrm{~mL}$ vs. $1 \mathrm{~mL}$ syringe). Higher dosing accuracy (lower dispensing error) was generally obtained with Propranolol $1 \mathrm{mg} / \mathrm{mL}$ in which the smaller syringe was used. 


\subsection{Viscosity}

The results regarding viscosity are presented in Figure 3. The viscosity of all formulations decreased with an increase in shear rate. The viscosity was affected by the amount of glycerol in the formulations and the viscosity increased with increased amounts of glycerol, which was expected due to the higher extent of hydrogen bonding in glycerol compared with water. For the oral liquids with the original composition (baseline), the viscosity was similar to the formulations containing $0 \%$ glycerol. The formulations with propranolol had a higher viscosity compared with the formulations with naloxone, which is probably due to the presence of sugar syrup in the propranolol formulations. Sugar syrup is used as a sweetener in oral liquids but also as a viscosity-increasing agent.
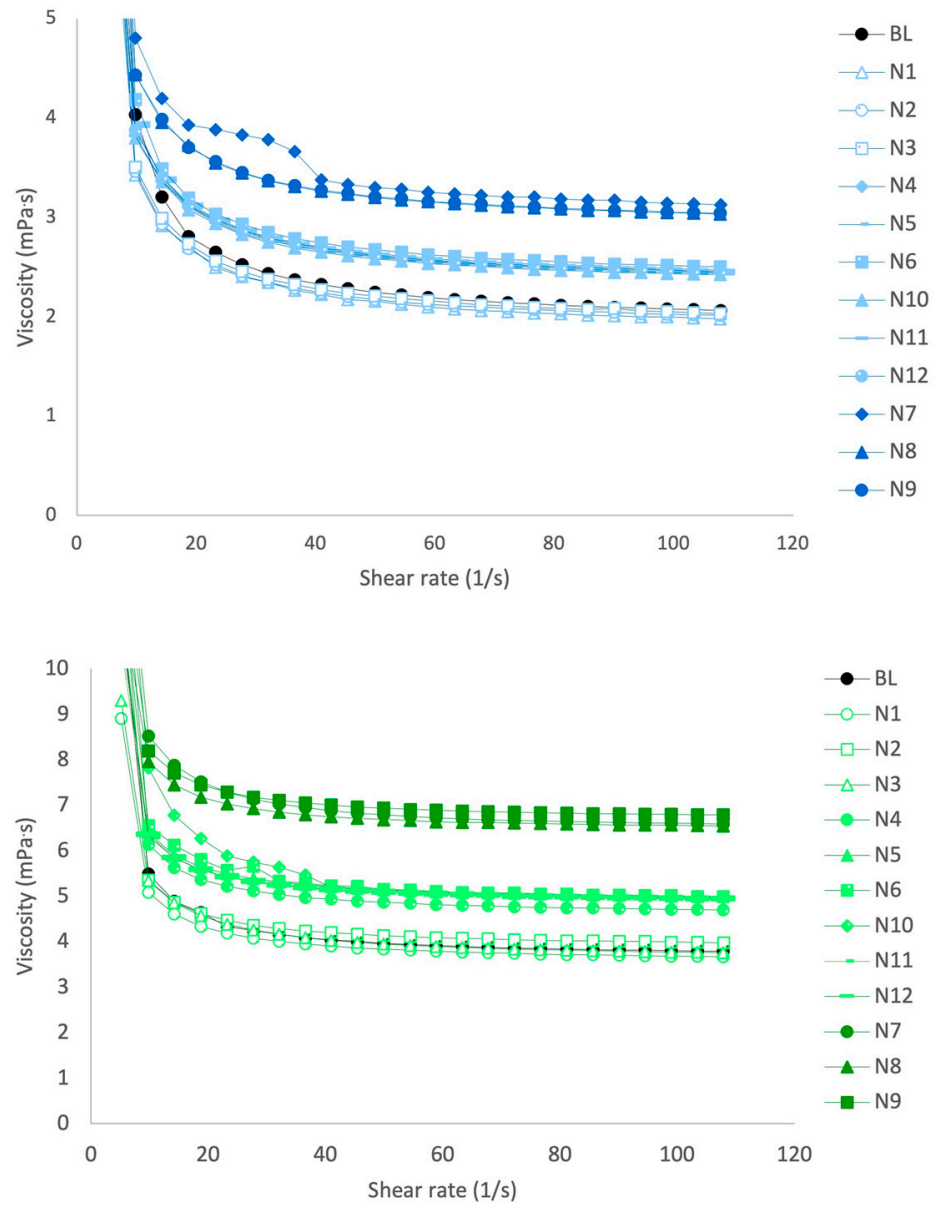

Figure 3. Viscosity as a function of shear rate for the oral liquids containing naloxone ((top figure), blue) and propranolol ((bottom figure), green) (mean value, $\mathrm{n}=2$ ). BL = baseline (original composition). Compositions of formulations N1-N12 according to Tables 4 and 5.

Viscosity has been reported to affect dosing accuracy, especially when using a cup or dropper compared with a syringe $[47,49]$. Higher viscosity of the oral liquid has been shown to decrease dosing accuracy which may potentially affect the administered dose [47,49]. Viscosity may also affect the acceptability and palatability of the formulation [17]. Although there were some differences in viscosity between the investigated formulations, all formulations obtained acceptable dosing accuracy. A higher viscosity did not have a negative impact on dosing accuracy in the present study, which may be due to a relatively low viscosity of the formulations and the relatively small difference in viscosity between the formulations. 


\subsection{Solubility}

Naloxone was insoluble in the oral liquids with pH 3 (N1, N4 and N7) and soluble in the oral liquids with $\mathrm{pH} 3.75$ and 4.5. Propranolol was insoluble in the oral liquids with $\mathrm{pH}$ 5 and $0 \%$ and $10 \%$ glycerol (N3 and N6) and soluble in the oral liquids with pH 5 and $20 \%$ glycerol and all oral liquids with $\mathrm{pH} 3$ and 4 . Apparently, the solubility of both naloxone and propranolol is $\mathrm{pH}$ dependent, and a suitable $\mathrm{pH}$ of the formulation must be chosen. The addition of glycerol did not generally have an effect on solubility, suggesting that $\mathrm{pH}$ is more important for the solubility of the drug substances compared with addition of a cosolvent/solubilizer. The observations indicated that it was possible to obtain solutions of both naloxone and propranolol given the right circumstances. Solubility was only determined visually which may have affected the interpretations due to the subjectivity of the method. In extemporaneous compounding, solubility is often determined by visual inspection. However, alternative methods to determine solubility, such as the shake-flask method, could provide a more objective analysis of solubility and is recommended in future studies.

\subsection{Osmolality}

Hyperosmolar oral liquids have been shown to cause gastrointestinal side effects such as feeding intolerance and delayed gastric emptying [18]. Osmolality should not exceed $700 \mathrm{mOsm} / \mathrm{kg}$ in oral liquids in order to minimize gastrointestinal side effects [18]. In newborns, osmolality around $400 \mathrm{mOsm} / \mathrm{kg}$ is desirable [53,54] and a recent review concluded that feed osmolality of 300-500 mOsm would not likely pose a safety risk to newborn infants [55]. However, a recent study showed that the osmolality of a majority of commonly used oral medication in neonates was greater than $500 \mathrm{mOsm} / \mathrm{kg}$ [56]. Thus, osmolality is an important property to take into consideration prior to administration of oral liquids. Osmolality could only be measured with the oral liquid containing propranolol and $0 \%$ glycerol since the osmometer could only measure osmolarities up to $2500 \mathrm{mOsm} / \mathrm{kg}$ (Table 6). The oral liquids containing propranolol and $10 \%$ and $20 \%$ glycerol had an osmolality exceeding $2500 \mathrm{mOsm} / \mathrm{kg}$. Osmolality of all the oral liquids containing naloxone could be measured. To be able to compare with propranolol, only osmolality for the oral liquids containing $0 \%$ glycerol is presented in Table 6 . The osmolality of formulations containing propranolol was higher than in formulations containing naloxone. Adding glycerol to the formulations containing naloxone resulted in increased osmolality (data not shown).

Table 6. Osmolality of the oral liquids containing naloxone and propranolol with $0 \%$ glycerol. Mean value \pm coefficient of variation $(n=2)$. Compositions of formulations N1-N3 according to Tables 4 and 5 .

\begin{tabular}{cccc}
\hline Naloxone $\mathbf{1 ~ m g / m L}$ & $\begin{array}{c}\text { Osmolality } \\
\text { (mOsm/kg) }\end{array}$ & $\begin{array}{c}\text { Propranolol } \\
\mathbf{1 0} \mathbf{~ m g / m L}\end{array}$ & $\begin{array}{c}\text { Osmolality } \\
\text { (mOsm/kg) }\end{array}$ \\
\hline Baseline & $136 \pm 0.007$ & Baseline & $983 \pm 0.005$ \\
N1 & $97 \pm 0.000$ & N1 & $1121 \pm 0.011$ \\
N2 & $96 \pm 0.000$ & N2 & $941 \pm 0.011$ \\
N3 & $81 \pm 0.000$ & N3 & $918 \pm 0.003$ \\
\hline
\end{tabular}

\subsection{Evaluation of Responses Using Multivariate Data Analysis}

To understand the effect of the selected variables on the selected responses, response contour plots were created using multivariate data analysis. The responses included were viscosity (mean value at $\left.20 \mathrm{~s}^{-1}\right)$, solubility $(1=$ soluble, $0=$ insoluble) and dispensed dose and the variables were $\mathrm{pH}$ and amount of glycerol (\%). With a DoE approach, it is possible to minimize the number of experiments and still gain valuable insights regarding the effect of formulation variables on the quality of the formulations. The goal is to develop an optimized formulation for the selected APIs by using multivariate data analysis. Figures 4 and 5 show the response contour plots for the oral liquids containing naloxone 
and propranolol, respectively. The results with naloxone showed that the best dispensed dose (dosing accuracy) can be obtained using compositions with either $0 \%$ or $20 \%$ glycerol and $\mathrm{pH} 3$ or compositions with $0 \%$ glycerol and $\mathrm{pH} 4.45$ (Figure 4 ). Viscosity increased with increasing amounts of glycerol and was independent of $\mathrm{pH}$ of the formulation (Figure 4). For naloxone to be soluble in the formulation, $\mathrm{pH}$ should be set to 3.75 or higher. Solubility of naloxone was independent of the amount of glycerol (Figure 4).
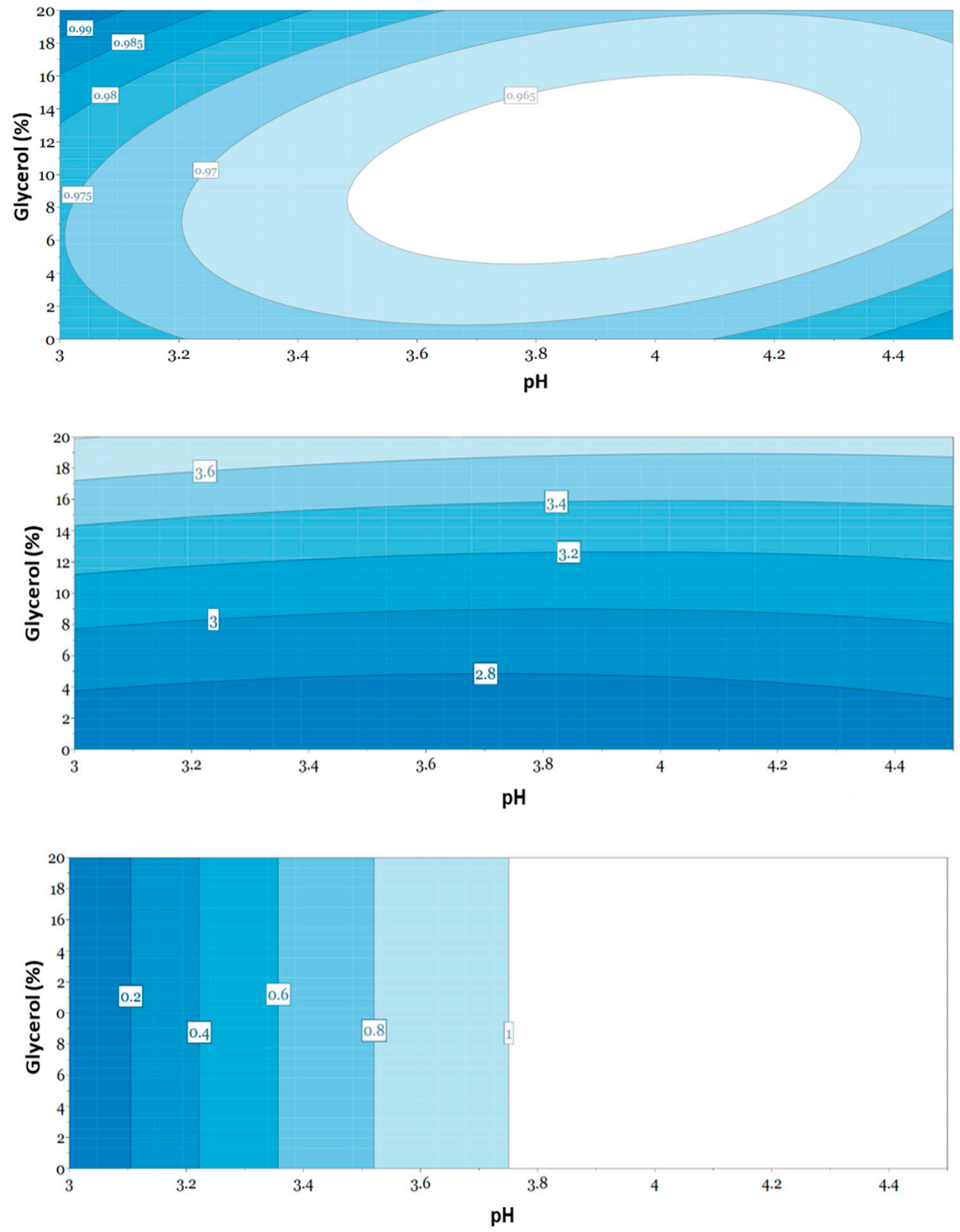

Figure 4. Response contour plot for responses dispensed dose (dosing accuracy) (top figure), viscosity (middle figure) and solubility (bottom figure) as a function of amount of glycerol and $\mathrm{pH}$. Compositions of formulations N1-N12 according to Table 4, containing naloxone. The target dose was $1 \mathrm{~mL}$, corresponding to $1 \mathrm{mg}$ naloxone. $\pm 10 \%$ of the intended dose was considered an acceptable dosing accuracy. Values above 1 in the solubility plot indicate that naloxone is soluble in the formulation, values below 1 indicate that naloxone is not soluble. 

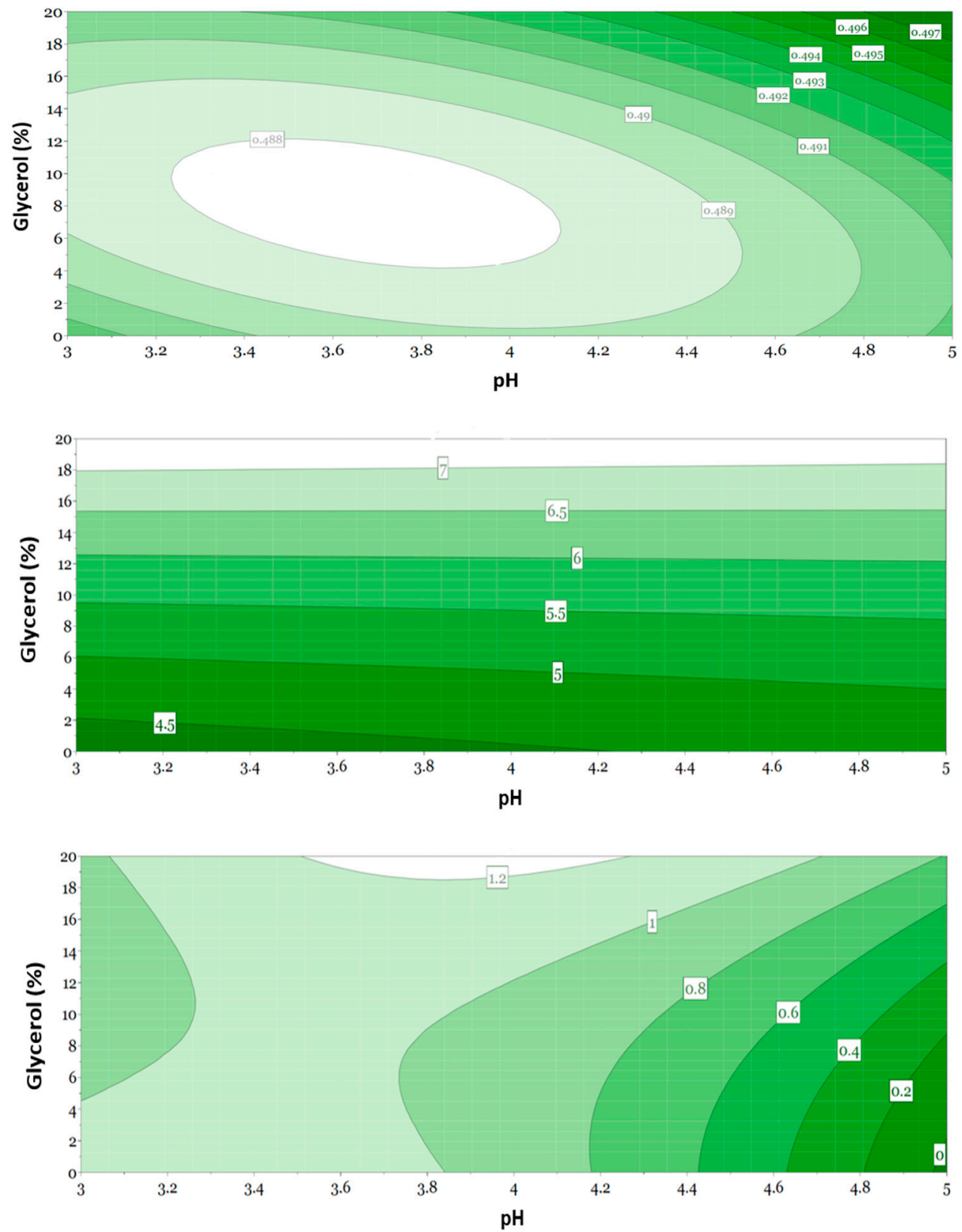

Figure 5. Response contour plot for responses dosing accuracy (dispensed dose) (top figure), viscosity (middle figure) and solubility (bottom figure) as a function of amount of glycerol and $\mathrm{pH}$. Compositions of formulations N1-N12 according to Table 5, containing propranolol. The target dose was $0.5 \mathrm{~mL}$, corresponding to $5 \mathrm{mg}$ propranolol. $\pm 10 \%$ of the target dose was considered an acceptable dosing accuracy. Values above 1 in the solubility plot indicate that propranolol is soluble in the formulation, values below 1 indicate that propranolol is not soluble.

The results with propranolol showed that the best dispensed dose (dosing accuracy) was obtained with compositions with pH 5 and $20 \%$ glycerol (Figure 5). Using $0 \%$ glycerol, the best dosing accuracy was obtained with compositions with $\mathrm{pH} 3$. Viscosity increased with increasing amount of glycerol and was independent of $\mathrm{pH}$ (Figure 5). For propranolol to be soluble in the formulations, $\mathrm{pH}$ should be set to 3-3.85 in compositions containing $0 \%$ glycerol (Figure 5).

\subsection{Evaluation of Selected Formulations}

Based on how the variables $\mathrm{pH}$ and amount of glycerol affected the responses solubility, dispensed dose and viscosity, optimal compositions were selected for naloxone and 
propranolol, respectively (Table 7). This selection was based on the interpretation of the contour plots, as described above, to identify a suitable amount of glycerol and suitable $\mathrm{pH}$ to be able to optimize the solubility, dispensed dose and viscosity of the liquids. When selecting the composition, the stability of API at different $\mathrm{pH}$ (Table 1) and the optimal $\mathrm{pH}$ of the selected preservative sodium benzoate (Figure 1) were also taken into consideration. Based on the results from the screening process, glycerol was chosen not to be included as a solubilizer because solubility of the API could be achieved without the addition of glycerol and glycerol increased the osmolality. The $\mathrm{pH}$ had an effect on solubility of the API and consequently, the $\mathrm{pH}$ of the oral liquids has to be optimized and an acceptable $\mathrm{pH}$-interval was therefore suggested (Table 7). $\mathrm{pH}$ in both the original and the optimized formulations is rather low. The literature suggests that $\mathrm{pH} 2-9$ can be tolerated in oral liquids [22] and studies have shown that oral liquids for pediatric use exhibit a wide range of $\mathrm{pH}$, from acidic to basic $[57,58]$. Previous studies have shown that $\mathrm{pH}$, as well as sweeteners, may cause erosive damage to the enamel surface of the teeth [57] and $\mathrm{pH}$ of oral liquids is therefore an important aspect to consider.

Table 7. Selected compositions of the two oral liquids after evaluation using multivariate data analysis.

\begin{tabular}{|c|c|c|}
\hline Preparation & Material & Amount \\
\hline \multirow[t]{4}{*}{ Naloxone $1 \mathrm{mg} / \mathrm{mL}$} & Naloxone hydrochloride dihydrate & $1 \mathrm{mg}$ \\
\hline & Sodium benzoate ${ }^{1}$ & 0.5 or $1 \mathrm{mg}$ \\
\hline & Hydrochloric acid $1 \mathrm{M}$ & q.s. pH 3.9-4.1 \\
\hline & Water, purified & ad $1 \mathrm{~mL}$ \\
\hline \multirow[t]{7}{*}{ Propranolol 10 mg/mL } & Propranolol hydrochloride & $10 \mathrm{mg}$ \\
\hline & Sodium citrate & $2.1 \mathrm{mg}$ \\
\hline & Citric acid monohydrate & $2.8 \mathrm{mg}$ \\
\hline & Sugar syrup & $320 \mathrm{mg}$ \\
\hline & Sodium benzoate ${ }^{1}$ & 0.5 or $1 \mathrm{mg}$ \\
\hline & Hydrochloric acid $1 \mathrm{M}$ & q.s. $\mathrm{pH} 3.2-3.6$ \\
\hline & Water, purified & ad $1 \mathrm{~mL}$ \\
\hline
\end{tabular}

${ }^{1} 0.05 \%$ and $0.1 \%$ sodium benzoate were tested. ad = to; q.s. (quantum satis) $=$ the amount which is enough.

The selected (optimized) compositions with two different amounts of sodium benzoate were characterized regarding dispensed dose (dosing accuracy), viscosity, osmolality (Table 8) and preservative effect (Tables 9 and 10). The results showed that dosing accuracy was acceptable for all selected formulations when dispensed using a syringe (Table 8). In the present study, drug content in each dose was not measured but it is suggested in future optimization studies to measure drug content with an appropriate analytical method. The viscosity and osmolality of the formulations appeared to be lower compared with the original compositions. However, since the measurements were made in duplicate, a more thorough statistical analysis is not possible, and interpretations should be made with caution.

As mentioned earlier, osmolality should not exceed $700 \mathrm{mOsm} / \mathrm{kg}$ in oral liquids to minimize gastrointestinal side effects [18]. The optimized formulations with naloxone all showed osmolalities well below $700 \mathrm{mOsm} / \mathrm{kg}$. However, the optimized formulations with propranolol had osmolalities above $700 \mathrm{mOsm} / \mathrm{kg}$. Despite this, gastrointestinal side effects have not been reported with Propranolol $10 \mathrm{mg} / \mathrm{mL}$ (original composition), suggesting a safe pediatric use also for the modified formulations. However, in future optimization studies, the high osmolality of the propranolol formulations should be addressed. 
Table 8. Characterization of the selected (optimized) compositions regarding dispensed dose (dosing accuracy), viscosity and osmolality. Mean value $\pm 95 \%$ confidence interval of dispensed dose ( $\%$ error) $(n=10)$, mean value \pm coefficient of variation of viscosity and osmolality $(n=2)$. Naloxone dose $=1 \mathrm{~mL}$ (corresponding to $1 \mathrm{mg}$ naloxone) and propranolol dose $=0.5 \mathrm{~mL}$ (corresponding to $5 \mathrm{mg}$ propranolol). Acceptable dosing accuracy (i.e., error in dispensed dose) was set to $\pm 10 \%$ of target dose.

\begin{tabular}{cccc}
\hline Preparation & $\begin{array}{c}\text { Dispensed Dose } \\
(\mathbf{m L})(\% \text { Error })\end{array}$ & Viscosity ${ }^{\mathbf{1}}$ (mPa.s) & $\begin{array}{c}\text { Osmolality } \\
\text { (mOsm/kg) }\end{array}$ \\
\hline Naloxone 1 mg/mL & & & \\
Baseline & $0.986 \pm 0.006(1.4)$ & $2.72 \pm 0.017$ & $136 \pm 0.007$ \\
SB 0.05\% & $0.959 \pm 0.008(4.1)$ & $2.60 \pm 0.008$ & $13 \pm 0.000$ \\
SB 0.1\% & $0.972 \pm 0.006(2.8)$ & $2.61 \pm 0.005$ & $22 \pm 0.000$ \\
\hline Propranolol 10 mg/mL & & & \\
Baseline & $0.487 \pm 0.004(2.6)$ & $4.48 \pm 0.016$ & $983 \pm 0.005$ \\
SB 0.05\% & $0.491 \pm 0.001(1.8)$ & $4.22 \pm 0.012$ & $933 \pm 0.002$ \\
SB 0.1\% & $0.491 \pm 0.001(1.8)$ & $4.31 \pm 0.015$ & $952 \pm 0.003$ \\
\hline
\end{tabular}

$\mathrm{SB}=$ sodium benzoate, $\mathrm{AV}=$ acceptance value, Baseline = original composition with methylparaben. ${ }^{1}$ At shear rate $201 / \mathrm{s}$.

Table 9. Microbiological challenge test for Naloxone $1 \mathrm{mg} / \mathrm{mL}$ with preservative sodium benzoate. Results expressed as $\log 10$ reduction after 14 and 28 days.

\begin{tabular}{|c|c|c|c|c|}
\hline Microorganism & $\begin{array}{l}\text { Amount Sodium } \\
\text { Benzoate }(\%)\end{array}$ & Start CFU/mL & $\begin{array}{c}\log _{10} \text { Reduction } \\
14 \text { Days }\end{array}$ & $\begin{array}{c}\log _{10} \text { Reduction } \\
28 \text { Days }\end{array}$ \\
\hline \multirow[t]{2}{*}{ Staphylococcus aureus } & 0.05 & $2.4 \times 10^{5}$ & 5 & NI \\
\hline & 0.1 & $2.4 \times 10^{5}$ & 5 & NI \\
\hline \multirow[t]{2}{*}{ Pseudomonas aeruginosa } & 0.05 & $2.8 \times 10^{5}$ & 5 & NI \\
\hline & 0.1 & $2.8 \times 10^{5}$ & 5 & NI \\
\hline \multirow[t]{2}{*}{ Escherichia coli } & 0.05 & $3.5 \times 10^{5}$ & 5 & NI \\
\hline & 0.1 & $3.5 \times 10^{5}$ & 5 & NI \\
\hline \multirow[t]{2}{*}{ Candida albicans } & 0.05 & $6.5 \times 10^{5}$ & 5 & NI \\
\hline & 0.1 & $6.5 \times 10^{5}$ & 5 & NI \\
\hline \multirow[t]{2}{*}{ Aspergillus brasiliensis } & 0.05 & $5.3 \times 10^{5}$ & 2 & NI \\
\hline & 0.1 & $5.3 \times 10^{5}$ & 5 & NI \\
\hline
\end{tabular}

Staphylococcus aureus (ATCC 6538), Pseudomonas aeruginosa (ATCC 9027), Escherichia coli (ATCC 8739), Candida albicans (ATCC 10231), Aspergillus brasiliensis (ATCC 16404) ATCC = American Type Culture Collection accession number; $\mathrm{CFU}=$ Colony Forming Unit; $\mathrm{NI}=$ No increase in number of viable microorganisms compared to the previous reading.

Table 10. Microbiological challenge test for Propranolol $10 \mathrm{mg} / \mathrm{mL}$ with preservative sodium benzoate. Results expressed as $\log _{10}$ reduction after 14 and 28 days.

\begin{tabular}{ccccc}
\hline Microorganism & $\begin{array}{c}\text { Amount Sodium } \\
\text { Benzoate (\%) }\end{array}$ & Start CFU/mL & $\begin{array}{c}\text { Log }_{10} \text { Reduction } \\
\text { 14 Days }\end{array}$ & $\begin{array}{c}\text { Log }_{10} \text { Reduction } \\
\text { 28 Days }\end{array}$ \\
\hline Staphylococcus aureus & 0.05 & $2.4 \times 10^{5}$ & 5 & NI \\
& 0.1 & $2.4 \times 10^{5}$ & 5 & NI \\
\hline Pseudomonas aeruginosa & 0.05 & $2.8 \times 10^{5}$ & 5 & NI \\
\hline Escherichia coli & 0.1 & $2.8 \times 10^{5}$ & 5 & NI \\
& 0.05 & $3.5 \times 10^{5}$ & 5 & NI \\
\hline Candida albicans & 0.1 & $3.5 \times 10^{5}$ & 5 & NI \\
& 0.05 & $6.5 \times 10^{5}$ & 5 & NI \\
\hline Aspergillus brasiliensis & 0.1 & $6.5 \times 10^{5}$ & 5 & NI \\
\end{tabular}

Staphylococcus aureus (ATCC 6538), Pseudomonas aeruginosa (ATCC 9027), Escherichia coli (ATCC 8739), Candida albicans (ATCC 10231), Aspergillus brasiliensis (ATCC 16404) ATCC = American Type Culture Collection accession number; $\mathrm{CFU}=$ Colony Forming Unit; NI = No increase in number of viable microorganisms compared to the previous reading. 
Results from the microbiological challenge tests are shown in Tables 9 and 10. For bacteria, a $\log _{10}$ reduction of at least 3 , and for fungi, a $\log _{10}$ reduction of at least 1 , are required after 14 days, and the number of viable microorganisms must not have increased after 28 days compared to the value at 14 days to show successful preservation [45]. All formulations with naloxone and propranolol passed the microbiological challenge test (Tables 9 and 10). The formulations with propranolol also contained sugar syrup which may contribute to the preservative effect since sugar has a preservative effect of its own. In addition, the sugar syrup used contains $0.1 \%$ methylparaben. Although the oral liquid with propranolol contains some methylparaben, it was chosen to be included in the study to be able to compare two different products and to investigate if it was possible to prepare the liquids in a similar way although the API differed. To totally exclude parabens from the propranolol formulation, sugar syrup should be removed or replaced. To increase the acceptability of the product among children, some other sweetening or flavoring agent could be considered, such as xylitol or sucrose. Another alternative is to use sugar syrup with a higher concentration (85\%) since this sugar syrup does not require any preservative. This is also applicable to the naloxone formulations since these does not contain any flavoring or sweetening agent. In the further development and optimization of the formulations, the overall acceptability and suitability of sweetening agents must be considered. There are safety issues related to use of sweeteners in drug formulations to pediatric patients, for example cariogenic and laxative effects [20].

There are no formal requirements to test extemporaneous formulations with respect to preservative effects since the shelf life of these products is short. Based on the stability data of up to 28 days storage and the rule of thumb that preservation should be conducted with as little preservative as possible, the lower amount of sodium benzoate, i.e., 0.05\%, is probably sufficient. The amount of sodium benzoate generally used in pharmaceutical products is $0.02-0.5 \%$ [40]. The effect of the preservative may decrease with time due to degradation and chemical instability, resulting in a decrease in the amount of preservative in the dosage form. Concerns have been raised regarding the safety of sodium benzoate in formulations intended for children [59]. Benzoic acid and benzoates could displace bilirubin from albumin thus increasing the risk of hyperbilirubinemia. This is especially of concern in neonates younger than eight weeks where metabolic enzymes are not fully matured [60]. The acceptable daily intake of benzoic acid and benzoates has been set to $0-5 \mathrm{mg} / \mathrm{kg}$ body weight $[61,62]$. In the formulations suggested in the present study, the amount of sodium benzoate is well below the acceptable daily intake based on pediatric dosing.

\section{Conclusions}

New compositions were suggested for Naloxone $1 \mathrm{mg} / \mathrm{mL}$ and Propranolol $10 \mathrm{mg} / \mathrm{mL}$ where methyl parahydroxybenzoate was replaced by sodium benzoate as preservative. The oral liquids containing sodium benzoate were shown to have satisfactory preservative properties during storage for up to 28 days. Glycerol was evaluated as a substitute for ethanol as a solubilizer but was not considered necessary to include in the new compositions since solubility of naloxone and propranolol could be achieved without addition of glycerol and glycerol increased osmolality. Furthermore, the oral liquids had an acceptable dosing accuracy. $\mathrm{pH}$ was rather low but within the tolerable range for oral liquids. In future formulation optimization studies of these oral liquids, aspects such as $\mathrm{pH}$, osmolality and taste should be further addressed.

Author Contributions: Conceptualization, S.M. and B.H.; methodology, S.M., M.A. and B.H.; validation, S.M. and B.H.; formal analysis, M.A.; investigation, M.A.; resources, B.H.; writing-original draft preparation, S.M., M.A. and B.H.; writing-review and editing, S.M.; visualization, S.M. and M.A.; supervision, S.M. and B.H.; project administration, S.M. and B.H. All authors have read and agreed to the published version of the manuscript.

Funding: This research received no external funding.

Institutional Review Board Statement: Not applicable. 
Informed Consent Statement: Not applicable.

Data Availability Statement: Not applicable.

Conflicts of Interest: The authors declare no conflict of interest.

\section{References}

1. Allen, H.C.; Garbe, M.C.; Lees, J.; Aziz, N.; Chaaban, H.; Miller, J.L.; Johnson, P.; DeLeon, S. Off-label medication use in children, more common than we think: A Systematic review of the literature. J. Okla State Med. Assoc. 2018, 111, 776-783. [PubMed]

2. Madathilethu, J.; Roberts, M.; Peak, M.; Blair, J.; Prescott, R.; Ford, J.L. Content uniformity of quartered hydrocortisone tablets in comparison with mini-tablets for paediatric dosing. BMJ Paediatr. Open 2018, 2, e000198. [CrossRef] [PubMed]

3. Zhao, N.; Zidan, A.; Tawakkul, M.; Sayeed, V.A.; Khan, M. Tablet splitting: Product quality assessment of metoprolol succinate extended-release tablets. Int. J. Pharm. 2010, 401, 25-31. [CrossRef]

4. $\quad$ Freeman, M.K.; White, W.; Iranikhah, M. Tablet splitting: A review of weight and content uniformity. Consult. Pharm. 2012, 27, 341-352. [CrossRef]

5. Nidanapu, R.P.; Rajan, S.; Mahadevan, S.; Gitanjali, B. Tablet splitting of antiepileptic drugs in pediatric epilepsy: Potential effect on plasma drug concentrations. Paediatr. Drugs 2016, 18, 451-463. [CrossRef] [PubMed]

6. Schier, J.G.; Howland, M.A.; Hoffman, R.S.; Nelosn, L.S. Fatality from administration of labetalol and crushed extended-release nifedipine. Ann. Pharmacother. 2003, 37, 1420-1423. [CrossRef] [PubMed]

7. Guideline on Pharmaceutical Development of Medicines for Paediatric Use. European Medicines Agency. 2014. Available online: https:/ / www.ema.europa.eu/en/documents/scientific-guideline/guideline-pharmaceutical-development-medicinespaediatric-use_en.pdf (accessed on 7 October 2021).

8. Reflection Paper: Formulations of Choice for the Paediatric Population. European Medicines Agency. 2006. Available online: https://www.ema.europa.eu/en/documents/scientific-guideline/reflection-paper-formulations-choice-paediatricpopulation_en.pdf (accessed on 7 October 2021).

9. Development of Paediatric Medicines: Points to Consider in Formulation. World Health Organization. 2012. WHO Technical Report Series; No 970, Annex 5. Available online: https://www.who.int/medicines/areas/quality_safety/quality_assurance/ Annex5TRS-970.pdf?ua=1 (accessed on 7 October 2021).

10. Ernest, T.B.; Elder, D.P.; Martini, L.G.; Roberts, M.; Ford, J.L. Developing paediatric medicines: Identifying the needs and recognizing the challenges. J. Pharm. Pharmacol. 2007, 59, 1043-1055. [CrossRef]

11. Van Riet-Nales, D.A.; Kozarewicz, P.; Aylward, B.; de Vries, R.; Egberts, T.C.G.; Rademaker, C.M.A.; Schobben, A.F.A.M. Paediatric drug development and formulation design-A European perspective. AAPS PharmSciTech 2017, 18, 241-249. [CrossRef]

12. Krause, J.; Breitkreutz, J. Improving drug delivery in paediatric medicine. Pharm. Med. 2008, 22, 41-50. [CrossRef]

13. Lopez, F.L.; Ernest, T.B.; Tuleu, C.; Gul, M.O. Formulation approaches to pediatric oral drug delivery: Benefits and limitations of current platforms. Expert Opin. Drug Deliv. 2015, 12, 1727-1740. [CrossRef]

14. Batchelor, H.K.; Marriott, J.F. Formulations for children: Problems and solutions. Br. J. Clin. Pharmacol. 2015, 79, 405-418. [CrossRef] [PubMed]

15. Tuleu, C.; Breitkreutz, J. Educational paper: Formulation-related issues in pediatric clinical pharmacology. Eur. J. Pediatr. 2013, 172, 717-720. [CrossRef] [PubMed]

16. Haywood, A.; Glass, B.D. Liquid dosage forms extemporaneously prepared from commercially available products-Considering new evidence on stability. J. Pharm. Pharm. Sci. 2013, 16, 441-455. [CrossRef] [PubMed]

17. Mistry, P.; Batchelor, H. Evidence of acceptability of oral paediatric medicines: A review. J. Pharm. Pharmacol. 2017, 69, 361-376. [CrossRef] [PubMed]

18. Klang, M.; McLymont, V.; Ng, N. Osmolality, $\mathrm{pH}$, and compatibility of selected oral liquid medications with an enteral nutrition product. J. Parenter. Enter Nutr. 2013, 37, 689-694. [CrossRef]

19. Salunke, S.; Brandys, B.; Giacoia, G.; Tuleu, C. The STEP (Safety and Toxicity of Excipients for Paediatrics) database: Part 2-the pilot version. Int. J. Pharm. 2013, 457, 310-322. [CrossRef]

20. Rouaz, K.; Chiclana-Rodríguez, B.; Nardi-Ricart, A.; Suñé-Pou, M.; Mercadé-Frutos, D.; Suñé-Negre, J.M.; Pérez-Lozano, P.; García-Montoya, E. Excipients in the Paediatric Population: A Review. Pharmaceutics 2021, 13, 387. [CrossRef]

21. Swarbrick, J.; Boylan, J.C. Encyclopedia of Pharmaceutical Technology; Marcel Dekker: New York, NY, USA, 1996; Volume 13, pp. 2983-2992.

22. Aulton, M.E.; Taylor, K.M. Aulton's Pharmaceutics-The Design and Manufacture of Medicine, 5th ed.; Churchill Livingstone Elsevier: Edinburgh, UK, 2013.

23. Zupanets, K.O.; Shebeko, S.K.; Ratushna, K.L.; Katilov, O.V. Cumulative Risks of Excipients in Pediatric Phytomucolytic Syrups: The Implications for Pharmacy Practice. Sci. Pharm. 2021, 89, 32. [CrossRef]

24. Batchelor, H.K.; Fotaki, N.; Klein, S. Paediatric oral biopharmaceutics: Key considerations and current challenges. Adv. Drug Deliv. Rev. 2014, 73, 102-126. [CrossRef]

25. Generally Recognized as Safe (GRAS). FDA. Available online: https://www.fda.gov/food/food-ingredients-packaging/ generally-recognized-safe-gras (accessed on 11 December 2021). 
26. Nowak, K.; Ratajczak-Wrona, W.; Górska, M.; Jabłońska, E. Parabens and their effects on the endocrine system. Mol. Cell Endocrinol. 2018, 474, 238-251. [CrossRef]

27. Reflection Paper on the Use of Methyl-and Propylparaben as Excipients in Human Medicinal Products for Oral Use. European Medicines Agency. 2015. Available online: www.ema.europa.eu (accessed on 15 October 2021).

28. Safety \& Toxicity of Excipients for Paediatrics database (STEP) London. European Pediatric Formulation Initiative. 2015. Available online: https:/ / step-db.ucl.ac.uk/eupfi/appDirectLink.do?appFlag=login (accessed on 17 October 2021).

29. Mulla, H.; Yakkundi, S.; McElnay, J.; Lutsar, I.; Metsvaht, T.; Varendi, H.; Nellis, G.; Nunn, A.; Duncan, J.; Pandya, H.; et al. An observational study of blood concentrations and kinetics of methyl- and propyl- parabens in neonates. Pharm. Res. 2015, 32, 1084-1093. [CrossRef] [PubMed]

30. Rasmussen, L.F.; Ahlfors, C.E.; Wennberg, R.P. The effect of paraben preservatives on albumin binding of bilirubin. J. Pediatr. 1976, 89, 475-478. [CrossRef]

31. Contreras, L.; Cram, A.; English, C.; Heimlich, J. Pharmaceutical Excipients in Pediatric Formulations. In Handbook of Pharmaceutical Excipients; Pharmaceutical Press: London, UK, 2016.

32. Whittaker, A.; Currie, A.E.; Turner, M.A.; Field, D.J.; Mulla, H.; Pandya, H.C. Toxic additives in medication for preterm infants. Arch. Dis. Child Fetal Neonatal. Ed. 2009, 94, 236-240. [CrossRef]

33. Valeur, K.S.; Hertel, S.A.; Lundstrøm, K.E.; Holst, H. The cumulative daily tolerance levels of potentially toxic excipients ethanol and propylene glycol are commonly exceeded in neonates and infants. Basic Clin. Pharmacol. Toxicol. 2018, 122, 523-530. [CrossRef]

34. Tissel, L.A. Handbook on Injectable Drugs, 13th ed.; Publications Production Center of the American Society of Health-System Pharmacists: Bethesda, MD, USA, 2005.

35. Drug Bank. The Governors of the University of Alberta. 2016. Available online: https://www.drugbank.ca/ (accessed on 13 December 2021).

36. Product Information Naloxone Hydrochloride Dihydrate. Sigma Aldrich. Available online: https://www.sigmaaldrich.com/ content/dam/sigma-aldrich/docs/Sigma/Product_Information_Sheet/2/n7758pis.pdf (accessed on 4 December 2019).

37. Product Information Propranolol Hydrochloride. Sigma Aldrich. Available online: https://www.sigmaaldrich.com/content/ dam/sigma-aldrich/docs/Sigma/Product_Information_Sheet/1/p5544pis.pdf (accessed on 4 December 2021).

38. Neuberger, J.M.; Schweitzer, S.; Rolland, M.O.; Burghard, R. Effect of sodium benzoate in the treatment of atypical nonketotic hyperglycinaemia. J. Inherit Metab Dis. 2000, 23, 22-26. [CrossRef] [PubMed]

39. Bateman, B.; Warner, J.O.; Hutchinson, E.; Dean, T.; Rowlandson, P.; Gant, C.; Grundy, J.; Fitzgerald, C.; Stevenson, J. The effects of a double blind, placebo controlled, artificial food colourings and benzoate preservative challenge on hyperactivity in a general population sample of preschool children. Arch. Dis. Child 2004, 89, 506-511. [CrossRef] [PubMed]

40. Wang, R.Y.; Chang, R.C.; Sowa, M.E.; Chang, A.C.; Abdenur, J.E. Prevention of metabolic decompensation in an infant with mutase deficient methylmalonic aciduria undergoing cardiopulmonary bypass. World J. Pediatr. 2014, 10, 83-85. [CrossRef] [PubMed]

41. Peltola, H.; Roine, I.; Fernandez, J.; Zavala, I.; Ayala, S.G.; Mata, A.G.; Arbo, A.; Bologna, R.; Mino, G.; Goyo, J.; et al. Adjuvant Glycerol and/or Dexamethasone to Improve the Outcomes of Childhood Bacterial Meningitis: A Prospective, Randomized, Double-Blind, Placebo-Controlled Trial. Clin. Infect Dis. 2007, 45, 1277-1286. [CrossRef]

42. Singhi, S.; Järvinen, A.; Peltola, H. Increase in serum osmolality is possible mechanism for the beneficial effects of glycerol in childhood bacterial meningitis. Pediatr. Infect Dis. J. 2008, 27, 892-896. [CrossRef]

43. Sankar, J.; Singhi, P.; Bansal, A.; Ray, P.; Singhi, S. Role of dexamethasone and oral glycerol in reducing hearing and neurological sequelae in children with bacterial meningitis. Ind. Pediatr. 2007, 44, 649-656.

44. Rowe, R.C.; Sheskey, P.J.; Quinn, M.E. Handbook of Pharmaceutical Excipients; The Pharmaceutical Press: London, UK, 2009.

45. European Pharmacopoeia, 10th ed.; Council of Europe: Strasbourg, France, 2019.

46. Tofil, N.M.; Benner, K.W.; Faro, S.J.; Winkler, M.K. The use of enteral naloxone to treat opioid-induced constipation in a pediatric intensive care unit. Pediatr. Crit. Care Med. 2006, 7, 252-254. [CrossRef] [PubMed]

47. Padden Elliott, J.; McConaha, J.; Cornish, N.; Bunk, E.; Hilton, L.; Modany, A.; Bucker, I. Influence of viscosity and consumer use on accuracy of oral medication dosing devices. J. Pharm. Technol. 2014, 30, 111-117. [CrossRef] [PubMed]

48. Sobhani, P.; Christopherson, J.; Ambrose, P.J.; Corelli, R.L. Accuracy of oral liquid measuring devices: Comparison of dosing cup and oral dosing syringe. Ann. Pharmacother. 2008, 42, 46-52. [CrossRef] [PubMed]

49. Peacock, G.; Parnapy, S.; Raynor, S.; Wetmore, S. Accuracy and precision of manufacturer-supplied liquid medication administration devices before and after patient education. J. Am. Pharm. Assoc. 2010, 50, 84-86. [CrossRef]

50. Neves, I.; Auxtero, M.D. Dosing Accuracy of Oral Extemporaneous Suspensions of Antibiotics: Measuring Procedures and Administration Devices. Pharmaceutics 2021, 13, 528. [CrossRef]

51. Berthe-Aucejo, A.; Girard, D.; Lorrot, M.; Bellettre, X.; Faye, A.; Mercier, J.C.; Brion, F.; Bourdon, O.; Prot-Labarthe, S. Evaluation of frequency of paediatric oral liquid medication dosing errors by caregivers: Amoxicillin and josamycin. Arch. Dis. Child 2016, 101, 359-364. [CrossRef]

52. Walsh, J.; Bickmann, D.; Breitkreutz, J.; Chariot-Goulet, M.; European Paediatric Formulation Initiative (EuPFI). Delivery devices for the administration of paediatric formulations: Overview of current practice, challenges and recent developments. Int. J. Pharm. 2011, 30, 221-231. [CrossRef] 
53. Fernández, P.A.; Cabañas, P.M.J.; Clemente, B.S.; Oliveras, A.M.; Castillo, S.F.; Hidalgo, A.E. Osmolality of oral liquid dosage forms to be administered to newborns in a hospital. Farm. Hosp. 2007, 31, 311-314. [CrossRef]

54. Barness, L.A.; Mauer, A.M.; Holliday, M.A.; Anderson, A.S.; Dallman, P.R.; Forbes, G.B.; Goldbloom, R.B.; Haworth, J.C.; Jesse, M.J.; Scriver, C.R.; et al. American Academy of Pediatrics. Commentary on breastfeeding and infant formulas, including proposed standards for formulas. Pediatrics 1976, 57, 278-285. [CrossRef]

55. Ellis, Z.M.; Tan, H.S.G.; Embleton, N.D.; Sangild, P.T.; van Elburg, R.M. Milk feed osmolality and adverse events in newborn infants and animals: A systematic review. Arch. Dis. Child Fetal Neonatal. Ed. 2019, 104, F333-F340. [CrossRef]

56. Shah, D.D.; Kuzmov, A.; Clausen, D.; Siu, A.; Robinson, C.A.; Kimler, K.; Meyers, R.; Shah, P. Osmolality of Commonly Used Oral Medications in the Neonatal Intensive Care Unit. J. Pediatr. Pharmacol. Ther. 2021, 26, 172-178. [CrossRef] [PubMed]

57. Zhao, D.; Tsoi, J.K.; Wong, H.M.; Chu, C.H.; Matinlinna, J.P. Paediatric Over-the-Counter (OTC) Oral Liquids Can Soften and Erode Enamel. Dent. J. 2017, 5, 17. [CrossRef] [PubMed]

58. Passos, I.A.; Sampaio, F.C.; Martínez, C.R.; Freitas, C.H. Sucrose concentration and pH in liquid oral pediatric medicines of long-term use for children. Rev. Panam. Salud Publica 2010, 27, 132-137. [CrossRef] [PubMed]

59. European Medicines Agency (EMA). Questions and Answers on Benzoic Acid and Benzoates Used as Excipients in Medicinal Products for Human Use. Committee for Medicinal Products for Human Use (CHMP). 2017. Available online: https://www.ema.europa.eu/en/documents/scientific-guideline/questions-answers-benzoic-acid-benzoates-usedexcipients-medicinal-products-human-use_en.pdf (accessed on 25 November 2021).

60. LeBel, M.; Ferron, L.; Masson, M.; Pichette, J.; Carrier, C. Benzyl alcohol metabolism and elimination in neonates. Dev. Pharmacol. Ther. 1988, 11, 347-356. [CrossRef]

61. Evaluation of Certain Food Additives and Contaminants, Forty-Sixth Report of the Joint FAO/WHO Expert Committee on Food Additives 1996, WHO Technical Report Series 868, World Health Organization, Geneva. Available online: https:/ /apps.who.int/ iris/handle/10665/41962/ (accessed on 21 January 2022).

62. Opinion of the Scientific Committee on Food on Benzoic acid and Its Salts, SCF/CS/ADD/CONS/48. European Commission, 2002. Available online: https:/ / ec.europa.eu/food/system/files/2020-12/sci-com_scf_out137_en.pdf (accessed on 21 January 2022). 